\title{
A revised, natural explanation for the Shroud of Turin image: creation of a composite Maillard reaction
}

\begin{abstract}
The Shroud of Turin is a large linen cloth bearing the full size image of a man with wounds corresponding to scourging and crucifixion. The molecular basis for the image on the cloth is unknown, although interestingly, the color only exists in a thin film on the fiber surface, less than 0.7 micrometers thick. In 2003, Rogers proposed that the Shroud image was the result of a Maillard reaction, involving interaction of free amines with reducing carbohydrates. Specifically, he suggested that a thin coating of crude starch and Saponaria residue on the surface of the cloth reacted with volatile amine-containing compounds arising from a body. Here, Rogers' Maillard hypothesis is (re)examined with the consideration of additional, contributing factors in the possible creation of the Shroud image.
\end{abstract}

Keywords: linen cloth, Maillard reaction, Shroud of Turin, Saponaria
Volume 5 Issue 5 - 2020

\author{
Kelly P Kearse \\ Science Department, Knoxville Catholic High School, USA
}

Correspondence: Kelly P Kearse, Science Department, Knoxville Catholic High School, USA, Knoxville Catholic High School, 9245 Fox Lonas Road, Knoxville, TN, USA, Phone: 865 560-03।3, Fax: 865-560-03|4,

Email kelly.kearse@knoxvillecatholic.com

Received: November 24, 2020 | Published: November 30, 2020

\section{Introduction}

The Shroud of Turin is an approximately fourteen foot long linen cloth containing the faint ventral and dorsal images of man imprinted on its surface (Figure 1). Throughout history, the Shroud has been heralded as both authentic and non-authentic, with various explanations put forth regarding the nature of the image, ranging from the natural to the supernatural. ${ }^{1-2}$ In 1978, the Shroud of Turin Research Project group (STURP) and additional scientists were allowed full access to the cloth for one hundred and twenty consecutive hours, the only examination of its kind that has ever been performed on this artifact. While collected data would eventually rule against the image being the result of a painting, a rubbing, or use of a heated metal statue, ${ }^{2-5}$ the nature of the image's creation remains enigmatic. Pellicori and Evans, who took many microphotographs during the examination, described the image as consisting of a "light sepia color with darkest coloration on the tops of the threads" ${ }^{6}$ All image areas are very faint; most image fibers are golden or yellow in color. A major conclusion from the 1978 examination was that, "It is clear that there has been a direct contact of the Shroud with a body, which explains certain features such as scourge marks, as well as the blood. However, while this type of contact might explain some of the features of the torso, it is totally incapable of explaining the image of the face with the high resolution that has been amply demonstrated by photography". ${ }^{7}$ It was noted that "the image is darkest in areas that should have been closest to the body's surface", $3,6,7$

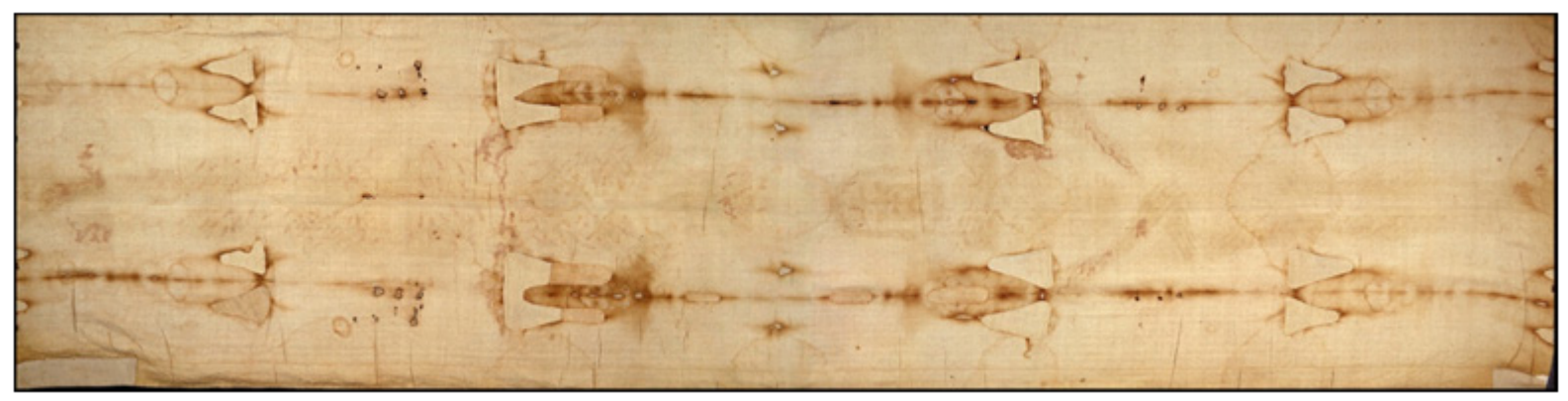

Figure I The Shroud of Turin. The ventral portion of the image is to the right and the dorsal portion is to the left. (C) 978 Barrie M. Schwortz Collection, STERA, Inc.

A member of the 1978 scientific team, Ray Rogers, who examined the Shroud in detail at both the macroscopic and microscopic levels, proposed that the image was the result of a Maillard reaction, ${ }^{8}$ occurring between free amine groups and a hemiacetal functional group, typically present in reducing sugars. Rogers proposed that the Shroud was treated with Saponaria, a softening agent used in the processing of ancient linen, which together with crude starch, left a thin coating of impurities on the cloth surface. ${ }^{5,8}$ Saponaria solution is known to contain multiple chemically reactive carbohydrates including galactose, glucose, arabinose, xylose, fucose, rhamnose, and glucuronic acid. ${ }^{5,9}$ Rogers suggested that volatile amine products from a body, such as ammonia, cadaverine, and putrescine, reacted with reducing sugars present on the cloth. The Maillard reaction is relatively complex, with multiple products generated in the interaction of a single type of carbohydrate with an individual amine bearing substrate, many of which remain to be fully characterized. ${ }^{5}$ Rogers 
was able to demonstrate that exposure of Saponaria-treated linen to ammonia vapors resulted in the coloring of threads with macroscopic and microscopic properties indistinguishable from those found on the Shroud, including the restriction of color to the uppermost portion of fibers. ${ }^{5,8}$ Although the presence of saponin remains to be directly demonstrated on the Shroud, it was suggested that the yellowish/green fluorescence observed under ultraviolet light is due to a thin residue of saponin on its surface. ${ }^{5,10}$ Interestingly, the colored coating of image fibers was stripped off by the adhesive present on the original sampling tapes; the insides of the fibers that remained were colorless. ${ }^{5,10}$ Such findings are consistent with removal of an impurity (colored) layer on the surface, distinct from the cellulose fiber itself. ${ }^{5}$ Rogers noted that the spectral evidence from the Shroud indicates that the image is a complex nature of melanoidins, and that many melanoidins, in general, have a highly unsaturated structure. ${ }^{11}$ This latter property is in agreement with the findings that Shroud image fibers could be decolorized by treatment with strong reducing agents. ${ }^{3,5,10}$

Rogers' Maillard hypothesis was proposed just a few years before his death in 2005, and one outstanding issue that still remains is whether diffusion of vapors would be sufficient to generate the detail that is observed in the Shroud image..$^{2,5,11}$ Recreations of how the Shroud might have wrapped a body demonstrate that the majority of the surface area is in contact with the cloth and that a strong correlation exists between the density of colored fibrils and the clothbody distance, ${ }^{2,12}$ i.e. the closer the cloth to the body, the darker the image. One component that was not considered in the original idea of Rogers is the potential contribution of amine-containing proteins/ peptides/amino acids in the outer layer of skin that could have also participated in image formation. Similar to ammonia, amino acids containing accessible amine groups may react with reducing sugars to create multiple products, including those that are devoid of nitrogen. The development of modern spray tanning methods is based on the reaction of applied reducing sugars with lysine, arginine residues found in keratin and other proteins in the outer dermal layer of the skin, ${ }^{13-17}$ demonstrating that substrates capable of participating in a Maillard reaction are available on the surface of the body. Other amino acids found in the stratum corneum (outer skin layer) may also participate in such reactions, including glycine, alanine, and histidine. ${ }^{13,14}$

Contemporary DNA analysis involving nucleic acid transfer by contact, "touch DNA", has revealed the efficiency of transmission of cellular products that may occur during even a brief interaction with an object. ${ }^{18-20}$ While most studies have focused on DNA transference, Stanciu and colleagues reported that $\sim 1 \times 10^{3}$ to $8 \times 10^{4}$ epidermal cells could be transferred from the interior of the hand after holding a sterile conical tube for only five minutes; washing of the skin beforehand led to even greater levels of cellular transfer, up to $1 \times 10^{5}$ cells. ${ }^{21}$ Williamson notes that "humans shed tens of thousands of skin cells each day and that these cells may be transferred to surfaces our skin contacts". ${ }^{18}$ Other estimates are much higher, at approximately 500 million. ${ }^{22}$ The Maillard reaction need not involve interaction with intact skin cells as proteins/peptides or free amino acids may react. ${ }^{13}$,

${ }^{14}$ Proteolysis is believed to be a principal event in the desquamation process, involving multiple proteases expressed in epidermal cells. ${ }^{23-26}$ Additionally, bacterial proteases present in the biofilm microflora on the skin assist in further protein breakdown, including those with keratinolytic activity. ${ }^{27}$ Taken together, these collective findings support the idea that transferal of proteins/peptides/amino acids originating from the surface of the body could provide additional substrates for the Maillard reaction proposed by Rogers, which, in turn, would increase the resolution and detail of the image on the cloth. Jointly, this "composite" Maillard reaction provides a revised, natural explanation for the image on the cloth, and extends Rogers' original model by suggesting a mechanism that could aid in enhancing the observed features, above that provided by vapor diffusion alone.

Finally, it has also been proposed that the chromophores responsible for the Shroud image are conjugated carbonyls resulting from oxidative dehydration of cellulose itself, with the coloration corresponding to the approximate depth of the primary cell well. ${ }^{2}$ Using short laser pulses in the ultraviolet, Di Lazzaro and colleagues have demonstrated superficial coloration of linen, ${ }^{28}$ although how a similar result might occur from a body is currently not well understood. If future sampling of the Shroud is permitted, a key goal would be to further characterize the nature of the image, i.e. to determine if it is due to surface impurities on the cloth, a change in the cellulose fibers themselves, or something else. Relatedly, if ancillary data is consistent with a Maillard reaction, it would be important to determine if Saponaria might have been involved as proposed by Rogers, or if other compounds/reducing sugars could have played a role. With a more complete understanding of the chemical nature of the image, attempts to determine the molecular basis of how it may have been created would have a more directed path to follow. In summary, the current report has (re)examined Rogers' Maillard hypothesis for image formation on the Shroud of Turin. Here, it is suggested that aminegroups from proteins/peptides/amino acids originating from the outer layer of skin may also function as substrates in the Maillard reaction. It is proposed that a "composite" Maillard reaction could provide a mechanism for additional resolution and detail in the Shroud of Turin image in the model originally suggested by Rogers.

\section{Acknowledgments}

Thank you to Barrie Schwortz for the photograph and for helpful discussion. As always, thank you to my wife Kathy, for everything.

\section{Funding}

None.

\section{Conflicts of interest}

Author declares that there is no conflict of interest.

\section{References}

1. Fanti G. Hypotheses regarding the formation of the body image on the Turin Shroud. A critical compendium. J Imaging Sci Technol. 2011;55:1-14

2. Jackson, J. Critical Summary of Shroud Observations, Data and Hypotheses. Colorado Springs, CO: Turin Shroud Center of Colorado Publishing; 2019.

3. Jumper EJ, Adler AD, Jumper EJ, et al. A comprehensive examination of the various stains and images on the Shroud of Turin. Archaeological Chemistry III, ACS Advances in Chemistry 205, 22, American Chemical Society, Washington DC; 1984. p. 447-476.

4. Meacham W. The authentication of the Turin Shroud, an issue in archaeological epistemology. Current Anthropology. 1983;24:283-285.

5. Rogers R. A Chemist's Perspective on the Shroud of Turin. USA: Raymond Rogers Publishing; 2008.

6. Pellicori S, Evans MS. The Shroud of Turin through the microscope. Archaeology. 1981;34-43.

7. Schwalbe LA, Rogers RN. Physics and chemistry of the Shroud of Turin, a summary of the 1978 investigation. Anal. Chim Acta. 1982;135:4-49. 
8. Rogers RN, Arnoldi A. The Shroud of Turin: An amino-carbonyl reaction (Maillard Reaction) may explain the image formation. Melanoidins vol. 4, Office for Official Publications of the European Communities, Luxembourg; 2003. p. 106-113.

9. Aziz MMAE, Ashour AS, Melad ASG. A review on saponins from medicinal plants: chemistry, isolation, and determination. J Nanomed Res. 2019;7:282-288.

10. Heller JH, Adler AD. A chemical investigation of the Shroud of Turin Can Soc Forens Sci J. 1982;14:81-103.

11. Heimburger T. Rogers' Maillard reaction hypothesis explained by Rogers himself. 2012.

12. Jackson JP, Jumper EJ, Ercoline WR. Correlation of Image Intensity on the Turin Shroud with the 3-D structure of a human body shape. Applied Optics. 1984;23:2244-2270.

13. Wittgenstein E, Berry HK. Reaction of dihydroxyacetone (DHA) with human skin callus and amino compounds. Science. 1960;132:894-895.

14. Bobrin MF, Martini MC, Cotte J. Effects of color adjuvants on the tanning effect of dihydroxyacetone. J Soc Cosmet Chem. 1984;35:265-272.

15. R V Lloyd, A J Fong, R M Sayre. In Vivo formation of Maillard reaction free radicals in mouse skin. J Invest Dermatol. 2001;117:740-742.

16. Ciriminna R, Fidalgo A, Ilharco LM, et al. Dihydroxyacetone: An updated insight into an important byproduct. Chemistry Open. 2018;7:233-236.

17. Garone M, Howard J, Fabrikant J. A review of common tanning methods. J Clin Aesthet Dermatol. 2015;8:43-47.
18. Williamson AL. Touch DNA: Forensic Collection and Application to Investigations. J Assoc Crime Scene Reconstr. 2012;18:1-5.

19. Van Oorscot RAH, Jones MK. DNA fingerprints from fingerprints. Nature. 1997;387:767.

20. Daly DJ, Murphy C, McDermott SD. The transfer of touch DNA from hands to glass, fabric, and wood. Forensic Sci Int Genet. 2012;6:41-46.

21. Stanciu CE, Philpott MK, Kwon YJ, et al. Optical characterization of epidermal cells and their relationship to DNA recovery from touch samples. F1000 Research. 2015;4:1360-1370.

22. Neuman T. Skin: How it works. 2018.

23. Suzuki Y, Nomura J, Hori J, et al. Detection and characterization of endogenous protease associated with desquamation of stratum corneum. Arch Dermatol Res. 1993;285:372-377.

24. Bragulla HH, Homberger DG. Structure and functions of keratin proteins in simple, stratified, keratinized and cornified epithelia. J Anat. 2009;214:516-519.

25. Eckhart L, Lippens S, Tschachler E, et al. Cell death by cornification. Biochimica et Biophysica Acta. 2013;1833:3471-3480.

26. Koziel J, Potempa J. Protease-armed bacteria in the skin. Cell Tissue Res. 2013;351:325-337.

27. Mikx FHM, De Jong MH. Keratinolytic activity of cutaneous and oral bacteria. Infection and Immunity. 1987;55:621-625.

28. Di Lazzaro P, Murra D, Nichelatti E, et al. Superficial and Shroudlike coloration of linen by short laser pulses in the vacuum ultraviolet. Applied Optics. 2012;51:8567-8578. 